\title{
Novo e bom: Volksduden. So schreiben wir richtig!
}

[New and good: Volksduden. So schreiben wir richtig]

http://dx.doi.org/10.1590/1982-8837220224

Félix Bugueño Miranda ${ }^{1}$

Volksduden. So schreiben wir richtig! Mannheim: Bibliographisches Institut, 2012 (960p.)

Uma vez mais, o Bibliographisches Institut Mannheim apresenta uma obra de referência para orientação no uso da língua ${ }^{2}$. Nesta oportunidade, é necessário destacá-lo, em parceria com o popular jornal Bild. A menção se faz necessária, pois a orientação no uso da língua, em especial considerando a complexa ortografia da língua alemã, só faz sentido se é a própria comunidade que sente a necessidade de receber essa orientação. $\mathrm{O}$ fato de o jornal Bild ter se associado à publicação de um dicionário eminentemente normativo (da norma ideal) prova que a linha editorial Duden possui uma legitimação inquestionável na comunidade germanófona. É por isso que a expressão Volksduden possui uma dupla significação: Por um lado, lembra que a orientação no uso da língua só faz sentido se ela se legitima pela e na comunidade linguística. Por outro lado, demonstra que um dos meios pelo qual essa orientação se torna um fato real é, dentre outros, quando essa mesma orientação é apresentada e executada pela imprensa.

Em relação ao dicionário, trata-se, como já foi mencionado, de um dicionário ortográfico e, nunca é demais deixar de mencioná-lo, foi com essa classe de dicionário que a série Duden começou a sua já longa tradição lexicográfica.

\footnotetext{
${ }^{1}$ Universidade Federal do Rio Grande do Sul, Instituto de Letras, Departamento de Línguas Modernas. Email: felixv@uol.com.br.

${ }^{2}$ Essa resenha faz parte de uma pesquisa sobre a lexicografia alemã, com apoio de uma bolsa de pesquisa CAPES/DAAD e desenvolvida junto ao Instituto de Romanística da Universidade de Paderborn /Alemanha.
} 
A primeira coisa a ser assinalada é que o Volksduden (doravante VDu (2012) ${ }^{3}$ ) apresenta um extenso Front Matter. Somos de opinião que o Front Matter, na sua tripla condição de explicitação da função do dicionário, de chamada de atenção para o usuário que almeja servir e de manual de instruções, deveria ser extremamente sucinto. O Front Matter de VDu, no entanto, possui um total de 13 páginas. A sua extensão, contudo, pode ser explicada parcialmente pela necessidade de oferecer um conjunto de orientações em relação à ortografia alemã, complexa por natureza.

Formalmente, o Front Matter se compõe de três grandes divisões. A primeira, intitulada "Como usar o dicionário" [Zur Wörterbuchbenutzung], contém um total de oito parágrafos que correspondem ao uso de signos especiais (parênteses, colchetes, etc.), aos critérios de lematização e, o que é mais importante, às instruções para interpretar informações gramaticais que servem à orientação no uso da língua. Dentre elas, destaca-se o referente aos princípios para reconhecer quando duas formas são igualmente preferenciais ou quando VDu considera que uma é a preferencial e a outra, a secundária (como s. v. Kassettenrekorder, Kassettenrecorder, em que as duas formas são igualmente legítimas, sugerindo-se simplesmente a forma com $-k$ - por sobre a forma com $-c-$, ou s. v. Kartograph, em que há uma remissão a Kartograf, considerando-se nesse caso, que a forma terminada em -ph é a forma claramente secundária e menos recomendada em favor da forma terminada em $-f$ ). Outro aspecto que explica a extensão do Front Matter é o conjunto de regras referentes ao uso de formas que ora podem ir separadas, ora podem constituir compostos. Dada a complexidade do tema, no VDu estão elencados um total de seis casos para ilustrar as situações de dúvidas. Três exemplos dos fenômenos escolhidos são: mithilfe / mit Hilfe; gewinnbringend / Gewinn bringend; Alleinerziehende / allein erziehende. Cada caso é sobejamente explicado através de uma linguagem simples e com exemplos. Nessa esteira, há também explicações referentes ao uso de hífen e de maiúsculas e minúsculas.

No que diz respeito à segunda e à terceira divisões, a segunda contém um índice de abreviaturas, e a terceira, um conjunto de regras sobre o uso da vírgula.

\footnotetext{
${ }^{3}$ Seguindo as convenções para trabalhos de lexicografia, foram adotadas duas decisões em relação à formatação do texto. Em primeiro lugar, os títulos de obras lexicográficas aparecem expressos por siglas. Em segundo lugar, as referências a verbetes de dicionários vão precedidas da abreviatura s.v. (sub voce, que quer dizer "queira ver no verbete").
} 


\section{Miranda, F. - Volksduden}

Quanto à nominata propriamente dita, e embora VDu advirta que um dicionário ortográfico quase não oferece segmentos informativos microestruturais, parece mais adequado analisar por separado a macro, micro e medioestrutura. Na verdade, há verbetes com um interessante conjunto de segmentos informativos.

Em relação à macroestrutura, VDu lematiza uma extensa gama de classes de unidades lexicais, tais como topônimos (Aachen, Aargau, Abesinien, Abu Dhabi, Milwalkee, Southampton etc.) e antropônimos (Aall, Aaron, Abelard, Afra etc.). Seguindo a tradição lexicológica da germanística, as contribuições lexicais de outras línguas ao alemão aparecem rigorosamente divididas entre estrangeirismos (Abbé, Abscence, After-Work-Party, Packstation, Savoir-vivre etc.) e empréstimos (Kammer, Kapitalismus, Pikarde, Saxofon, Traktat etc.). Na maioria dos casos, a leitura atenta do verbete permite compreender a razão da lematização. No caso dos estrangeirismos, particularmente, a indicação etimológica é um claro sinal de que VDu julga (com razão) que a palavra em questão pode oferecer dúvidas quanto à sua ortografia ou separação silábica. No entanto, é para se questionar a lematização de antropônimos como Milhaud e Trakl (embora seja evidente a dificuldade fonética e ortográfica que oferece a primeira dessas formas), já que não se tratam de formas frequentes no alemão (aparecem com baixíssima frequência no corpus Projekt Deutscher Wortschatz (http://wortschatz.unileipzig.de) e não apresentam ocorrência alguma no corpus LIMAS (http://www. korpora.org./LIMAS/, por exemplo).

Especialmente interessantes são os casos de palavras destacadas em caixinhas de diálogo, tais como s. v. Abend, abwärts, achtzig, kahl, kalt, photo / Photo. No caso de Abend, o tratamento em uma caixinha de diálogo se deve a sua dupla condição morfológica de substantivo e advérbio. Para ajudar na discriminação entre a forma com maiúscula e a forma com minúscula, são oferecidas combinações sintagmáticas ou frases em que as duas formas costumam aparecer, como, por exemplo, des, eines Abends, am Abend (pela função de nominalização que supõem o artigo e a preposição), ou na frase von morgen bis abends etc. S. v. kalt, por sua vez, além das possibilidades de grafar kalt com maiúscula e minúscula, há indicações para os casos em que kalt se mantém separado em relação a alguns verbos («das Wetter war kalt geblieben»), assim como os casos em que kalt forma um trennbares Verb (kaltlassen, kaltmachen, kaltstellen etc.). Finalmente, a caixinha de diálogo pode servir também para a orientação 


\section{Miranda, F. - Volksduden}

ortográfica, como s.v, photo / Photo («Das ph in den aus dem Griechischen stammenden Wörtern mit «photo» kann generell durch f ersetzt werden»).

Tal como comentado já, um dicionário ortográfico possui um programa constante de informações (o conjunto total de segmentos informativos) extremamente simples, normalmente integrado ao lema (a palavra em negrito). No entanto, no caso de $\mathrm{VDu}$, esse programa se expande bastante segundo as particularidades de cada lema. No Front Matter (p. 7), comenta-se que a lematização se fez atendendo ao critério de frequência, à dificuldade ortográfica e à dificuldade gramatical que cada lema apresentasse. Nessa esteira, verbetes como Abzug, lieferbar e Taucher apresentam unicamente a forma ortográfica canônica, a acentuação prosódica (sob a forma de um ponto debaixo da vogal tônica) e a separação silábica (por exemplo: Ạb $\mid \mathbf{z u g}$ ). Em outros casos, os verbetes exibem um número maior de segmentos informativos. Os lemas Messtichblatt e Offenmarktpolitik, por exemplo, oferecem marcas de uso («Mẹss $\mid$ tisch | blatt (veraltend für topographische Karte im Maßtab 1: 25000»)). Mais interessantes são dois casos muito sintomáticos da lexicografia alemã como um todo e, particularmente, da tradição Duden. Em primeiro lugar, a transcrição fonética s.v. Academie française («Aca $|\mathbf{d e}|$ mie fran $\mid$ çaise [...de...frã’s ${ }^{\prime}$ :z], die; - - 〈franz.〉 (Akademie für französische Sprache und Literatur)»). Ao se tratar de um estrangeirismo, VDu foi consequente com o princípio de fornecer todas as informações necessárias para a sua correta representação gráfica e fônica. Em segundo lugar, e mais interessante ainda, é o conjunto de segmentos informativos fornecidos em muitos verbetes vernáculos (particularmente verbos), e não somente para o falante nativo, mas também para o aprendiz de alemão como língua estrangeira. Eis alguns exemplos: kümmern, nachschlagen, reden, scheuen, schicken, spielen. S. v. reden, por exemplo, é oferecida uma rica fraseologia: rẹ|den; gut reden haben; von sich reden machen; jmdn. zum Reden bringen; nicht viel Redens von einer Sache machen; Reden ist Silber, Schweigen ist Gold. Por sua vez, s. v. scheuen há também informações referentes ao padrão sintático do verbo: scheu | en; sich scheuen; das Pferd hat gescheut; ich habe mich vor dieser Arbeit gescheut. A única observação crítica a ser feita em relação às informações fornecidas nesses e em outros muitos verbetes é a ausência de marcadores não estruturais (recursos para marcar ou realçar um segmento informativo) que ajudem na eficiente decodificação de cada um dos segmentos informativos presentes no verbete. É prudente assinalar que os segmentos polifuncionais são um fato característico e um 


\section{Miranda, F. - Volksduden}

ponto discutível de toda a tradição Duden e, por que não dizê-lo, da lexicografia alemã como um todo. O emprego massivo de indicadores não estruturais daria a cada segmento informativo o efeito de saliência necessário.

Um último ponto a ser destacado é o alto índice de remissões presente no VDu. Isso ocorre porque em muitos casos existe mais de uma forma possível para uma dada unidade léxica, o emprego de mecanismos medioestruturais (de remissão) se torna quase inevitável. A maior dificuldade na utilização desses mecanismos está no fato de que não são eficientemente empregados (remissões que não fazem sentido, que não resolvem o problema linguístico que levou à consulta do dicionário, que são circulares, etc., são alguns exemplos desse problema). No caso de VDu, as remissões são justificadas em todos os casos, já que o impulso de remissão (o porquê se emprega esse mecanismo) está claramente justificado no Front Matter. Assim, por exemplo, s. v. Glucose aparece a seguinte remissão: «vgl. Glukose». A razão da remissão tem a ver como o fato que, em VDu (p. 8), o consulente é informado que os casos de remissão remetem à forma tida como preferencial: Glukose (forma germanizada do helenismo). Em outros casos,

como s.v. gleichfalls, há uma remissão a Fall (gleich|falls $v g l .{ }^{1}$ Fall), em que são fornecidos os exemplos de uso de maiúscula e minúscula para os compostos de Fall.

Em síntese, pode-se afirmar, sem sombra de dúvida, que novamente um expoente da linha editorial Duden oferece uma obra extremamente útil. Trata-se de um dicionário claro na sua exposição, cogitado em relação às dúvidas que a complexa ortografia do alemão suscita não somente no aprendiz, mas no falante nativo também. Além disso, embora essa classe de obras se limite ao comentário de forma (o lema considerado somente como significante), VDu oferece também valiosas informações sobre o potencial sintagmático (em sentido lato) das palavras. A deficiência apontada nesse quesito, no entanto, e como comentado já, parece ser um problema endêmico da lexicografia alemã. Em nada tira o mérito da obra resenhada. A germanística só tem a agradecer.

Recebido em 06/08/2014 aceito em 19/09/2014 